\title{
Maturity and spawning of Atlantic chub mackerel Scomber colias in M'diq Bay, Morocco
}

\author{
Mohamed Techetach ${ }^{1 *}$, Hafid Achtak ${ }^{1}$, Fatima Rafiq ${ }^{1}$, Abdallah Dahbi ${ }^{1}$, Rabia Ajana ${ }^{2}$, and \\ Younes Saoud ${ }^{2}$ \\ ${ }^{1}$ Environment and Health Team, Department of Biology, Polydisciplinary Faculty of Safi, Cadi \\ Ayyad University, Sidi Bouzid District, P.O. Box 4162, 46000, Safi, Morocco \\ ${ }^{2}$ Applied Biology and Pathology Laboratory, Department of Biology, Faculty of Sciences, \\ Abdelmalek Essaadi University, 93002, Tetouan, Morocco
}

\begin{abstract}
Knowledge of reproductive parameters is necessary to understand the ecology, the population dynamics and to enable rational management of fish of economic interest. This work is a contribution to the study of some aspects of the reproductive biology of the Atlantic mackerel Scomber colias (Gmelin, 1789) in the Mediterranean Moroccan coast. The study is based on samples taken from commercial catches in M'diq Bay. The spawning period was determined following both the monthly changes of the gonadosomatic index and the histological maturity stages. The Atlantic chub mackerel spawn between November and March, with maximum activity in December.
\end{abstract}

\section{Introduction}

The Atlantic chub mackerel Scomber colias (Gmelin, 1789) is a costal pelagic species. It is frequent over the continental slope from the surface to $300 \mathrm{~m}$ depth. The S. Colias is a gregarious and migratory species. It is widely distributed in the warm waters of the Atlantic Ocean, the Mediterranean Sea and the Black Sea. In the eastern Atlantic, chub mackerel occurs between the Bay of Biscay and South Africa [1]. Recently, genetic divergence and phenotypic variation has been demonstrated that Scomber japonicus and Scomber colias were distinct. Indeed, $S$. japonicus traditionally considered as a cosmopolitan species, their distribution is localized in the Indian and Pacific oceans [2, 3].

The Atlantic chub mackerel is one of the most important fishery resources in the Moroccan coasts, where is fished mainly by purse seiners. The total catch of S. Colias was 225500 tons in Moroccan waters, which represent $19 \%$ of the whole landing of small pelagic fish [4]. Despite the socio-economic and ecological interest, researches on mackerel biology and ecology in the Moroccan coasts are very limited.

The optimal temperature for spawning activity of mackerel is $15-20{ }^{\circ} \mathrm{C}$ [1]. For the reproductive success, the strategy of mackerel is characterized by being gonochoric, iterparous, oviparous, multiple batch spwaner with indeterminate fecundity [5]. Knowledge of the characteristics of the reproductive biology of mackerel is an important basis for understanding the population dynamics and rational management of this species. However,

\footnotetext{
* Corresponding author: mtechetach $@$ gmail.com
} 
information on its reproductive biology is still scarce and fragmentary for the Mediterranean stock [5, 6, 7, 8, 9]. Thus, the main objective of the present study was to describe the spawning season of $S$. colias, and to conduct a comparative analysis with results previously obtained.

\section{Materials and methods}

Samples of Atlantic chub mackerel were collected in $\mathrm{M}^{\prime}$ diq region $\left(35^{\circ} \mathrm{N}, 5^{\circ} \mathrm{W}\right)$ from purse seiners catches. A total of 845 individuals were collected between January and December 2004 and specimens were obtained from weekly collections. For each fish, both total length (TL, $1 \mathrm{~mm}$ ) and body weight (TW, $0.1 \mathrm{~g}$ ) were measured. Sex determination was made by visual examination of the gonads. The gonads were removed, weighed (total weight, 0.1 $\mathrm{mg}$ ), and ovaries were fixed in $10 \%$ buffered neutral formalin for subsequent histological processing. Sections of the ovaries $(5 \mu \mathrm{m})$ were stained with Harris Haematoxylin and counterstained in eosin to determine maturity stages and to follow the stage of gonadic maturity. No difference was found in maturation stage in respect to ovary position [10].

Temporal patterns in female and male gonad development were followed using the gonadosomatic index (GSI) according to [11]:

$$
\% \text { GSI = Gonad weight }(g) / \text { Body weight }(g) \times 100
$$

The statistical analyses were made using the Statistica software v.6.0. Analysis of variance (ANOVA) was used to test the difference in GSI between males and females.

\section{Results}

\subsection{Sample composition}

Of the total fish samples examined, $53.61 \%$ were females and $46.39 \%$ were males. The length of fish ranged between 16.4 and $35.9 \mathrm{~cm}$ TL, while their weight varied from 31.6 to $489.7 \mathrm{~g}$ TW.

\subsection{Seasonal fluctuations of gonadosomatic index}

The monthly variation in the mean GSI is shown in Figure 1. The GSI fluctuated throughout the year and revealed an increase in reproductive activity in November until March. The maximum average GSI value was obtained in December for both sexes. However, the low values were recorded between April and October. The comparison between sexes was also informative. Females had GSI values significantly higher than those of males $(P<0.05)$. In fact, their GSI ranged from 0.01 to 4 compared to 0.005 to 4.22 for males. A similar monthly evolution in GSI was evident for females and males. 

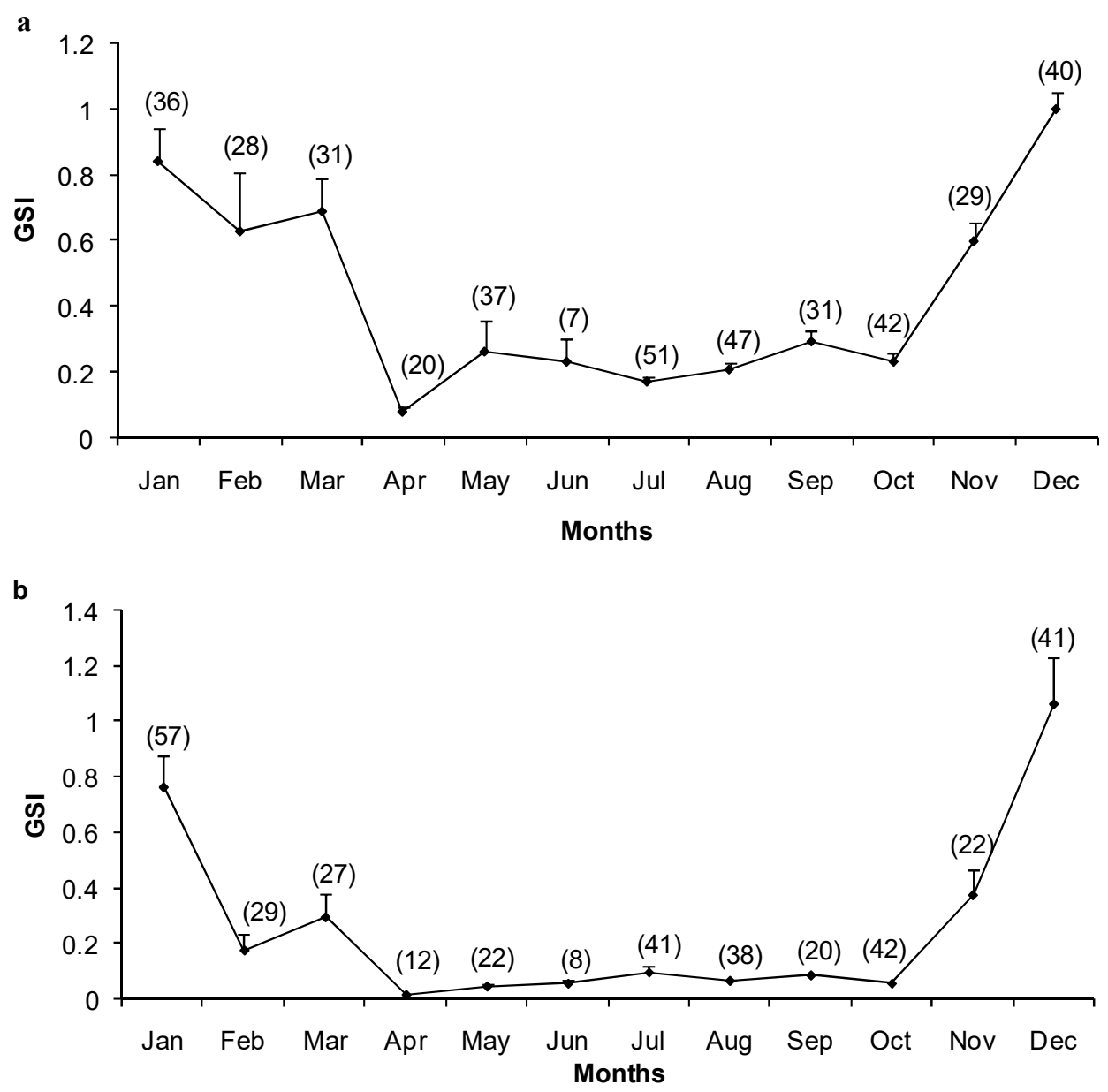

Fig. 1. Variation in gonadosomatic index (GSI) of S. colias: (a) Females; (b) Males. Vertical bars indicate standard deviations. Figures in parentheses indicate sample sizes.

\subsection{Seasonal changes in the maturation of the ovaries}

Histological classification of the ovaries was based on the developmental stage of the most advanced oocytes [12]. Four phases were assigned to the ovaries: (1) immature, (2) maturing, (3) spawning and (4) spent. The Atlantic chub mackerel has an asynchronous ovary containing oocytes at different stages of development.

The monthly distribution of the histological ovaries maturity stages of $S$. colias revealed the occurrence of immature individuals throughout the year. Females in the maturing and spawning stages were collected between November (72.41\%) and March (20.83\%) with a peak in December (100\%) (Fig. 2). 


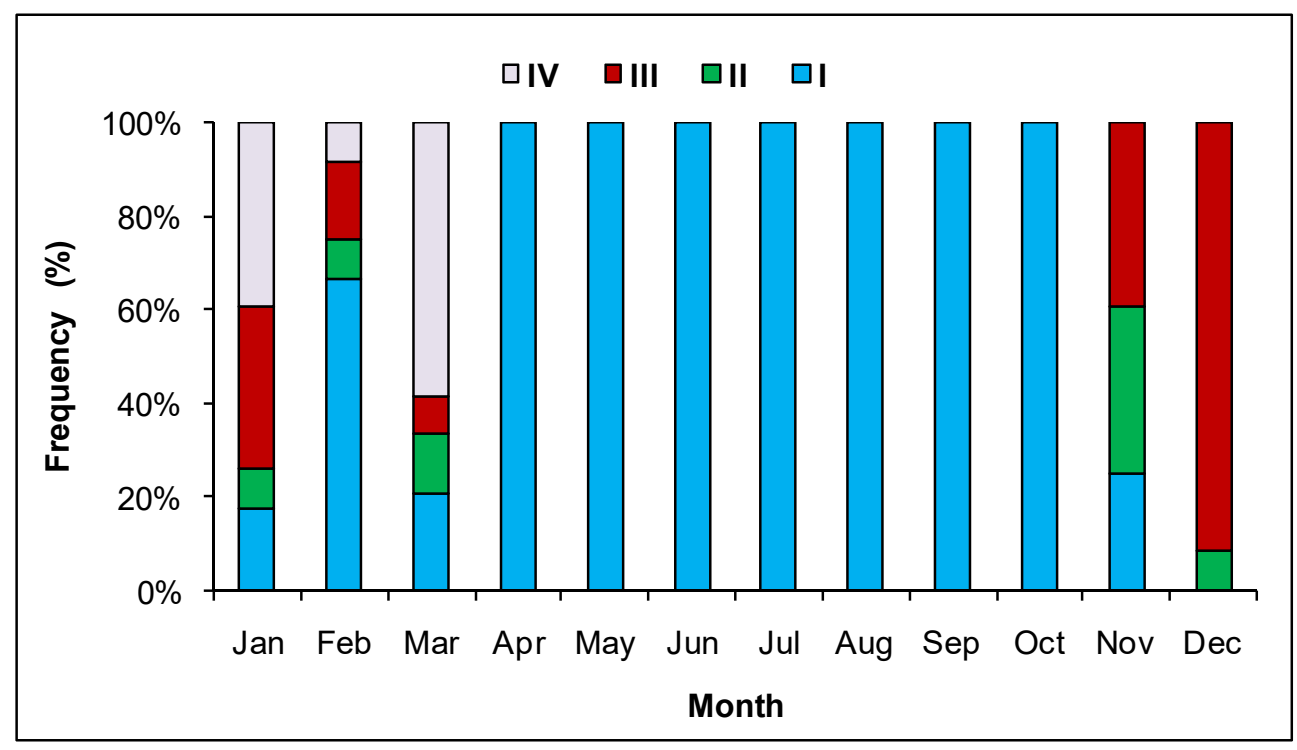

Fig. 2. Temporal variation in the distribution of the ovary maturity stages I-IV for S. colias.

\section{Discussion}

Scomber colias of M'diq Bay is gonochoric, without evidence of sexual dimorphism. The histological study showed that this species has an asynchronous ovarian organisation.

The present results on the monthly variation of the gonadosomatic index and ovarian maturity stages revealed that the spawning period of Atlantic chub mackerel in the study area extended from November to March and peaking in December. These results is in agreement with previous studies $[13,14,15]$, but are discordant with other investigations. In fact, the Atlantic chub mackerel living in Adriatic Sea spawn during the spring and summer seasons, with peak spawning in June [16]. In Tunisian waters, a closer ecosystem, this species was shown to be biannually spawning in winter and in summer $[17,18]$. Interestingly, in Moroccan North Atlantic coast, the spawning season was shown to occur in tow annual periods. The first period was from December to March, whereas the second period was concentrated in June-July [19]. These differences in spawning period between different regions (e.g. the Mediterranean and Atlantic coasts) might be related to the variation in ecological factors like water temperature and quality and abundance of nutriments [20]. According to [21], temperature appears to be the most determinant environmental factor influencing the reproduction of fish.

Higher GSI values were found in females than in males. Variation in GSI indicates the relative allocation of energy between somatic and gonadal growth [22]. This suggests that females have a higher energy allocation for gonadal development relative to males, such patterns also observed in other teleost fishes [23].

The Atlantic chub mackerel seem to have a prolonged spawning period in the Mediterranean Sea. This strategy is related probably to warming of the sea. Additionally, we must highlighted that success of any fish spawning depend of many environmental factors such as water temperature, food availability and upwelling indices. However, the ecological significance of such difference between populations needs more investigation including more geographical areas. 


\section{Conclusions}

The information gathered in this study contributes to specify the reproductive period of Atlantic chub mackerel $S$. colias. This pelagic species has a long spawning season during the year (five months), which might affect the behavioural schools of fish as a whole. The results of this study could be fundamental and constitute a baseline to improve the assessment and management of this marine resource in the Moroccan Mediterranean coast.

\section{References}

1. B. B. Collette, C. E. Nauen, FAO Species Catalogue. Vol. 2. FAO Fish Synop 125, 137 (1983)

2. C. Infante, E. Blanco, E. Zuasti, A Crespo, M. Manchado, Genetica 130, 1-8 (2007)

3. G. Catanese, M. Manchado, C. Infante, Gene 452, 35-43 (2010)

4. I.N.R.H, Rapport annuel de l'état des stocks et des pêcheries marocaines. DRH (2015)

5. M. Techetach, R. Ajana, Y. Saoud, J. Mar. Biol. Assoc. UK 99, 957-962 (2019)

6. M. Tuggaç, CGPM 4. Débats et Doc Techn 21, 145-159 (1957)

7. N. Demir, Rapports et Procès-verbaux des réunions 2, 313-316 (1961)

8. R. Mužinic R, Pomorski zbornik 17, 613-632 (1979)

9. S. Kiparissis, G. Tserpes, N. Tsimenidis, Belg. J. Zool 130, 3-7 (2000)

10. T. Yamada, I. Aoaki, I. Mitani, Fisheries Research 38, 83-89 (1998)

11. R. O. Anderson, S.J. Gutreuter, Fisheries Techniques. American Fisheries Society, Bethesda, 283-300 (1983)

12. S. K. Lowerre-Barbieri, K. Ganias, F. Saborido-Rey, H. Murua, J. R. Hunter, Mar. Coast. Fish 3, 71-91 (2011)

13. B. Habashi, J. Wojciechowski, ICES CM 20, 1-9 (1973)

14. J. M. Lorenzo, J. G. Pajuelo, Afr. J. Mar. Sci 17, 275-280 (1996)

15. F. Wahbi, A. Errhif, O. Ettahiri, Symposium on Science and the Challenge of Managing Small Pelagic Fisheries on Shared Stocks in Northwest Africa, 11-14 March 2008, Casablanca, Morocco, 127-138 (2011)

16. V. Cikes Kec, B. Zorica, J. Appl. Ichthyol 28, 12-21 (2012)

17. A. Hattour, Contribution à l'étude des poissons pélagiques des eaux tunisiennes. $\mathrm{PhD}$ thesis, Faculty of sciences of Tunis, Tunisia (2000)

18. H. Allaya, A. Hattour, G. Hajjej, M. Trabelsi, Afri. J. Biotechnol 12, 3040-3048 (2013)

19. M. Techetach, J. A. Hernando-Casal, Y. Saoud, M. H. Benajiba, Cybium 34, 159-165 (2010)

20. G. V. Nikolsky, The ecology of fishes. Academic Press, London (1963)

21. R. J. Wootton, Ecology of teleost fishes. Londres: Chapman and Hall (1990)

22. M. C. Yin, Fish ecology. Beijing, China Agriculture Press (1993)

23. V.M. Lemos, A. S. Varela Junior, G. Velasco, J. P. Vieira, Zoologia 28, 603-609 (2011) 